\title{
Potential Efficacy of Thymosin $\alpha 1$ in the Treatment of Lymphocytopenia and T Cell Exhaustion Associated with COVID-19
}

\author{
Milad Shirvaliloo ${ }^{1}$ \\ ${ }^{1}$ Affiliation not available
}

July 6, 2020

\begin{abstract}
It is not unbeknownst to us that since the very onset of the COVID-19 outbreak, many patients from different age groups have suffered greatly, and in a remarkable number of cases, succumbed to their untimely demise as a result of infection with the novel coronavirus or SARS-CoV-2. The elderly are perhaps the most vulnerable group of people, who stand at the pinnacle of morbidity and mortality rates due to contracting severe forms of COVID-19. Hopefully, based on the recent findings and the present evidence, there might be a number of medications that would possibly be of great prophylactic and therapeutic value to the elderly patients diagnosed with COVID-19. According to an interventional study, Thymosin $\alpha 1$ is arguably one such medication that has recently been indicated to be an effective therapeutic agent for inpatient correction of lymphocytopenia and $\mathrm{T}$ cell exhaustion caused by COVID-19.
\end{abstract}

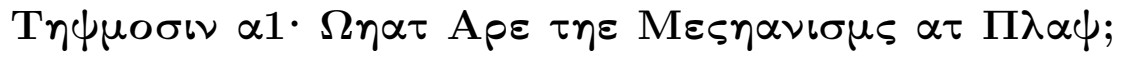

COVID-19 is associated with a wide spectrum of symptoms and lab findings, that may vary from one patient to another. Lymphocytopenia is an important lab finding in patients with acute COVID-19, that might be accompanied by $\mathrm{T}$ cell exhaustion, which is defined by substandard function of T cells. An immune-related complication of cancer and infections, such as COVID-19, T cell exhaustion is a vicious state characterized by inappropriate up-regulation of inhibitory receptors, e.g., programmed cell death protein 1 (PD-1), and a transcriptional activity that is simply inadequate for an effector $\mathrm{T}$ cell to be functioning properly. Thus, exhaustion seriously interferes with optimal containment of infections by cell-mediated immunity (1). Since lymphocytes are the key players in containment of viral infections, patients with exhausted $\mathrm{T}$ cells are more inclined to develop a disease with poor prognosis (2).

Another detrimental complication of COVID-19 is an insidious fall in the count of lymphocytes present in the thymus. This is mostly observed in the elderly patients, above 60 years old, with severe COVID-19 who often require intensive care (3). The decline in the population of lymphocytes residing in the thymus may be accompanied by concomitant dysregulation of thymic activity, and a consequential decrease in the diversity of T cell receptors, known collectively as "TCR repertoire". In fact, reduced thymic activity is a major culprit responsible for the failure of immune reconstitution following long-term antiretroviral therapy in patients infected with human immunodeficiency virus (HIV) (4). As a result, the patients might become incapacitated in terms of immunity, that would render them vulnerable to other viral infections (5).

Thymosin $\alpha 1$ is a hormone with a polypeptide make-up, that is produced in the epithelial cells of the thymus. This regulatory macromolecule exerts a positive effect on the count of $\mathrm{T}$ cells and their differentiation in the thymus, while also negatively regulating their rate of apoptosis or programmed cell death (6). As a 
medication, Thymosin $\alpha 1$ has clinically been tested on patients with HIV-1 infection, and is said to be of potential therapeutic value in restoring immune homeostasis in these patients (7).

The salutary effects of Thymosin $\alpha 1$ is attributed to its function as a modifier of the immune response. Recently, a pioneering interventional study by Y. Liu et. al., evaluated the therapeutic value of this hormone in treatment of COVID-19 patients with severe disease, and reported relatively satisfactory results, that are quite noteworthy.

In experimental treatment of COVID-19, Thymosin $\alpha 1$ is allegedly characterized by a triad of therapeutic outcomes:

1. It lessens the patient mortality rate. The study reported significantly different mortality rates, 11 and 30 percent, for two groups of severely ill COVID-19 patients, that received the same treatment regimen, except for Thymosin $\alpha 1$. Continuous daily administration of Thymosin $\alpha 1$ for a week resulted in better levels of $\mathrm{PO}_{2}$ (partial pressure of oxygen), and a significantly lower mortality rate in the treatment group; which indicates a roughly 3-fold higher response to treatment with Thymosin $\alpha(8)$.

2. It improves the $\mathbf{T}$ cell count in patients with lymphocytopenia. Thymosin $\alpha 1$ is quite effective in the hospital management of the aged patients who manifest a fall in their lymphocyte count as a consequence to SARS-CoV-2 infection. However, the most optimal therapeutic results are only achieved with patients who have a $\mathrm{CD} 8^{+} \mathrm{T}$ cell count below $400 / \mu \mathrm{L}$, or a $\mathrm{CD} 4^{+} \mathrm{T}$ cell count below $650 / \mu \mathrm{L}(8)$.

3 . It counteracts the $\mathbf{T}$ cell exhaustion occurring in the thymus. Thymosin $\alpha 1$ has a negative regulatory effect on the expression of PD-1 and " $\mathrm{T}$ cell immunoglobulin and mucin domain-containing protein 3" (TIM-3) (8). PD-1 and TIM-3 are two inhibitory receptors, that are usually expressed on the surface of exhausted $\mathrm{T}$ cells, a relatively common phenomenon in acute viral infections (9). Evaluation of the patient peripheral blood samples through flow cytometry indicated lower quantities of PD-1 and TIM-3 on the surface of the T cells in the treatment group. The constructive effect of Thymosin $\alpha 1$ in correction of $\mathrm{T}$ cell exhaustion is thought to be mediated through the enhancement of naïve $\mathrm{T}$ cells originating in the thymus. This idea was further supported once the study was able to trace TRECs in the peripheral blood mononuclear cells of the patients, who had been treated with Thymosin $\alpha 1$ (8). TRECs or "T cell receptor excision circles" are specific small circles of DNA that are generated in the $\mathrm{T}$ cells during the rearrangement of their receptors in the thymus (10). This finding suggests that Thymosin $\alpha 1$ might be capable of enhancing the thymic output. The exact mechanism behind this effect of Thymosin $\alpha 1$ is yet to be elucidated, however.

To this date, Thymosin $\alpha 1$ has clinically been used in treatment of several ailments associated with dysregulation of $\mathrm{T}$ cells, e.g., autoimmune diseases, viral infections, and even aging. There is also evidence regarding the efficacy of Thymosin $\alpha 1$ in treatment of Acute Respiratory Distress Syndrome (ARDS) in patients with Cytomegalovirus (CMV) infection following kidney transplantation, who similarly had developed lymphocytopenia (11).

\section{Conclusion}

With due attention to our literature and the recent findings in the wake of the COVID-19 outbreak, it can be postulated that Thymosin $\alpha 1$ might be of great clinical value in management of patients with progressed disease, especially the elderly who are more vulnerable to complications such as lymphocytopenia and ARDS as a result of SARS-CoV-2 infection. The positive regulatory effect of this thymic hormone in development and proliferation of $\mathrm{T}$ cells is a well-known fact that cannot be overlooked, especially amid the COVID19 pandemic. Further research and clinical trials are required to shed more light on the effectiveness of Thymosin $\alpha 1$ at improving patient survival in a world afflicted with COVID-19.

Keywords : Thymosin $\alpha 1$, Lymphocytopenia, T cells, COVID-19, SARS-CoV-2

\section{References}

1. Wherry EJ. T cell exhaustion. Nature Immunology. 2011;12(6):492-9. doi:10.1038/ni.2035 
2. Huang C, Wang Y, Li X, Ren L, Zhao J, Hu Y, et al. Clinical features of patients infected with 2019 novel coronavirus in Wuhan, China. The Lancet. 2020;395(10223):497-506. doi:10.1016/S0140-6736(20)30183-5

3. Liu K, Chen Y, Lin R, Han K. Clinical features of COVID-19 in elderly patients: A comparison with young and middle-aged patients. Journal of Infection. 2020;80(6):e14-e8. doi: 10.1016/j.jinf.2020.03.005

4. Li T, Wu N, Dai Y, Qiu Z, Han Y, Xie J, et al. Reduced Thymic Output Is a Major Mechanism of Immune Reconstitution Failure in HIV-Infected Patients After Long-term Antiretroviral Therapy. Clinical Infectious Diseases. 2011;53(9):944-51. doi:10.1093/cid/cir552

5. Yager EJ, Ahmed M, Lanzer K, Randall TD, Woodland DL, Blackman MA. Age-associated decline in T cell repertoire diversity leads to holes in the repertoire and impaired immunity to influenza virus. Journal of Experimental Medicine. 2008;205(3):711-23. doi:10.1084/jem.20071140

6. Garaci E. From thymus to cystic fibrosis: the amazing life of thymosin alpha 1. Expert Opinion on Biological Therapy. 2018;18(sup1):9-11. doi:10.1080/14712598.2018.1484447

7. Matteucci C, Grelli S, Balestrieri E, Minutolo A, Argaw-Denboba A, Macchi B, et al. Thymosin alpha 1 and HIV-1: recent advances and future perspectives. Future Microbiology. 2017;12(2):141-55. doi:10.2217/fmb-2016-0125

8. Liu Y, Pang Y, Hu Z, Wu M, Wang C, Feng Z, et al. Thymosin alpha 1 (T $\alpha 1$ ) reduces the mortality of severe COVID-19 by restoration of lymphocytopenia and reversion of exhausted $\mathrm{T}$ cells. Clinical Infectious Diseases. 2020. doi:10.1093/cid/ciaa630

9. McLane LM, Abdel-Hakeem MS, Wherry EJ. CD8 T Cell Exhaustion During Chronic Viral Infection and Cancer. Annual Review of Immunology. 2015;37(1):457-95. doi:10.1146/annurev-immunol-041015-055318

10. Serana F, Chiarini M, Zanotti C, Sottini A, Bertoli D, Bosio A, et al. Use of V(D)J recombination excision circles to identify $\mathrm{T}$ - and B-cell defects and to monitor the treatment in primary and acquired immunodeficiencies. Journal of Translational Medicine. 2013;11(1):119. doi:10.1186/1479-5876-11-119

11. Ji SM, Li LS, Sun QQ, Chen JS, Sha GZ, Liu ZH. Immunoregulation of Thymosin $\alpha 1$ Treatment of Cytomegalovirus Infection Accompanied With Acute Respiratory Distress Syndrome After Renal Transplantation. Transplantation Proceedings. 2007;39(1):115-9. doi: 10.1016/j.transproceed.2006.10.005 